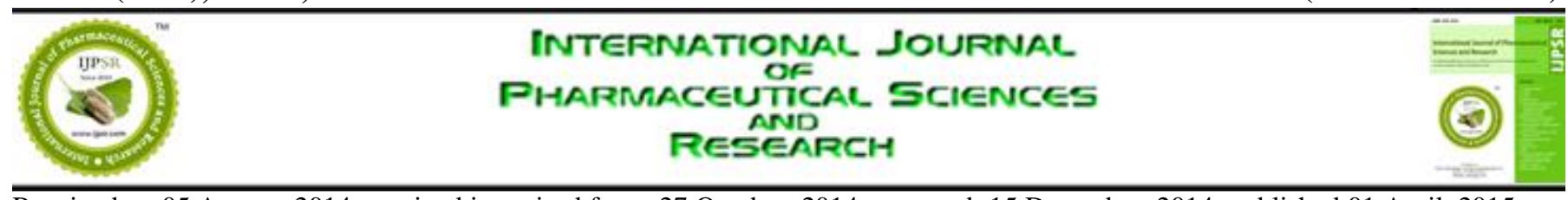

Received on 05 August, 2014; received in revised form, 27 October, 2014; accepted, 15 December, 2014; published 01 April, 2015

\title{
EVALUATION OF ANTIMICROBIAL ACTIVITY OF PLANT EXTRACTS
}

\author{
Suvarna Vasanti
}

Department of Pharmaceutical Chemistry, S.V.K.M'S, Dr. Bhanuben Nanavati College of Pharmacy, Mithibhai College Campus, V.M. Road. Vile Parle- (W), Mumbai - 400 056, India

Keywords:

Mangifera indica Linn, Ixora parviflora Vahl,

Correspondence to Author:

Dr. Priya Senan V

Assistant Professor \& Head,

Post Graduate Department of

Biotechnology, SAS SNDP Yogam

College, Konni-689 691

Pathanamthitta, Kerala, India

E-mail: vasantimmsuvarna@yahoo.com

\begin{abstract}
The objective of this study was to evaluate the possible antimicrobial properties of water, methanol, chloroform and Petroleum ether extracts of leaves of different Indian medicinal plants including Mangifera indica Linn, Ixora parviflora Vahl, Psydium guajava Linn, Calotropis procera Ait. The extracts were investigated individually for in vitro antibacterial activity by cup plate (well diffusion) method against nine pathogenic bacteria cultures. Of all the plants investigated for antimicrobial potential, the leaf extracts of Psydium guajava showed high antimicrobial activity against the tested microorganisms. Methanolic leaf extract of Psydium guajava was found to exhibit highest antimicrobial activity. Water leaf extracts of Mangifera. Indica and Ixora parviflora did not show antimicrobial activity. Phenolic content of Psydium guajava could contribute towards its antibacterial activity. The antibacterial activities of the investigated plants could make it useful in microbial infections.
\end{abstract}

INTRODUCTION:Although many communicable diseases have been effectively contained, bacterial infection remains a major cause of morbidity and mortality particularly in developing countries ${ }^{1}$. Problems with drug resistant microorganisms, side effects of modern drugs and emerging diseases where no medicines are available have stimulated renewed interest in plants as significant source of new medicines ${ }^{2}$. Many research works have been reported which aim at knowing the different antimicrobial constituents of medicinal plants and using them for the treatment of microbial infections as possible alternatives to synthetic drugs to which many infectious microorganisms have become resistant ${ }^{3}$.

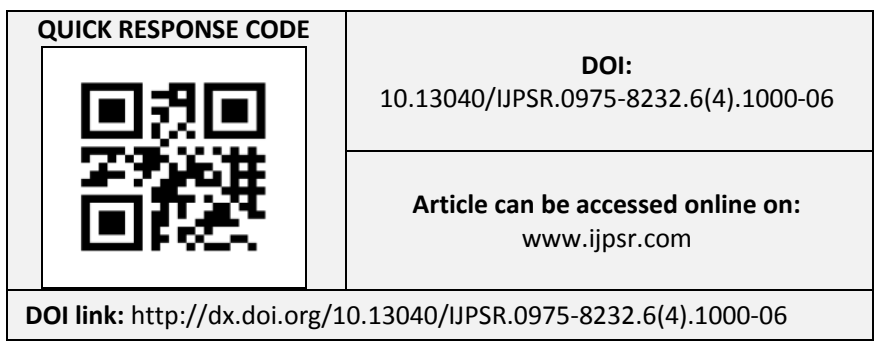

Psidium guajava known as 'apple of the tropics' belonging to family Myrtaceae is used in folk medicine to treat wounds, ulcers, toothache gum boils, cholera, cerebral affections, nephritis, epilepsy, convulsions etc. and is reported to be used as an astringent for bowels and tonic in digestive dysfunctions ${ }^{4}$ Phytochemical constituents isolated from the leaves of Psidium guajava include tripenoids, approximately $10 \%$ tannin, quercetin (+)-galoocatechin. The antimicrobial activities of Psydium guajava leaf extracts against Bacillus subtilis, Staphylococcus aureus, Escherichia coli and Pseudomonas aeruginosa and acne-developing organisms is reported 5 . Traditionally the ash of burned leaves of Mangifera indica Linn is used as household remedy for burns and scalds. The leaves are also masticated to give tone to the gums. Fumes from the burned leaves are inhaled for relief from hiccups and affections of the throat ${ }^{6}$.

In literature the leaves are reported to contain terpenoidal saponins, glucosides magniferine, and $0.1 \%$ of viscous dark red volatile oil ${ }^{6}$. No much biological and chemical work is reported for Ixora 
parviflora Vahl. Its Leaves are reported to be used in diarrhoea ${ }^{7}$. In folk medicine, the leaves of Calotropis procera are used to alleviate ear pain. Ethanolic extract of the leaves exhibited high mortality against nematode, Cephalobus litoralis. Methanolic extract is reported to exhibit antibacterial and antifungal activity. Leaves contain proteolytic enzymes and thiol activated proteinase 4 .

The plant contains cardenolide, proceragenin which is reported to exhibit antibacterial activity ${ }^{8}$. The aim of this work was to assess the antimicrobial properties of the various extracts of leaves of medicinal plants Mangifera indica Linn, Ixora parviflora Linn, Psydium guavaja Linn and Calatropis procera Ait against a broader spectrum of microbial pathogens of human relevance.

\section{MATERIALS AND METHODS:}

\section{Plant material:}

The leaves of Mangifera indica, Linn, Ixora parviflora, Linn, Psydium guavaja Linn and Calatropis procera Ait used for the study were collected from the campus of Dr. Bhanuben Nanavati College of pharmacy, Mumbai and were cleaned, shade dried at room temperature for 10-15 Days. The plant parts were authenticated by Dr. Bindu Gopal Krishnan of botany department of Mithibai College, Vile Parle(W), Mumbai-56. The plant materials were coarsely powdered and stored in airtight containers.

\section{Extraction:}

Dried and coarsely powdered plant materials, (25 gm of each sample) were individually extracted in muslin bags with various solvents such as petroleum ether, chloroform, methanol and water by using continuous hot extraction with Soxhlet extractor, for $18 \mathrm{hrs}$. The crude extracts obtained were filtered through Whatman paper no .1 and the filtrates were evaporated under reduced pressure and low temperature to give a gummy solid residue. The dried extracts were weighed and stored in labelled sterile screw capped bottles in refrigerator.

\section{Preparation of test solution:}

Accurately weighed dried extracts were dissolved in dimethyl sulfoxide (DMSO) in sterile test tubes to obtain concentration of $100 \mathrm{mg} / \mathrm{ml}$ and subjected to antimicrobial screening.

\section{Test organisms:}

The isolated bacterial cultures used in the screening such as Bacillus subtilis, Staphylococcus aureus, Klebsiella pneumoniae, Proteus vulgaris, Pseudomonas aeruginosa, Escheritia coli, Salmonella typhi, Bacillus cereus, Sarcina lutea were procured from the Department of Microbiology, Mithibhai College of Sciences, Mumbai, Maharashtra. These cultures were characterized using morphology, staining techniques and biochemical tests.

\section{Culture media:}

The media used for antimicrobial testing was Nutrient agar of Hi-media Pvt. Ltd. Mumbai, India.

\section{Inoculum preparation:}

The bacterial cultures were maintained on nutrient agar slants (Hi-media Pvt. Ltd. Mumbai, India) in refrigerator making monthly transfers. Inocula of the test organisms were prepared by inoculating a loopful of organism from $24 \mathrm{hrs}$ old cultures of nutrient agar slants incubated at $37^{\circ} \mathrm{C}$ into sterile saline. The turbidity was matched with 0.5 McFarland standard, which corresponds to $1.5 \mathrm{X}$ $10^{8} \mathrm{CFU} / \mathrm{ml}^{10}$. One $\mathrm{ml}$ of this suspension was diluted aseptically to $10 \mathrm{ml}$ with sterile saline to give culture density of about $10^{7} \mathrm{CFU} / \mathrm{ml}$.

\section{Anti-microbial Screening:}

The plant extracts were tested for antimicrobial activity by the cup plate / well plate diffusion method ${ }^{9}$ using nine bacterial cultures. $0.1 \mathrm{ml}$ of bacterial suspension was thoroughly mixed with 25 ml of sterile molten Nutrient Agar (Hi-media Pvt. Ltd) respectively and poured in presterilized petri plates and set aside. After congealing the seeded agar was punched out (Dug out) with flamed cork borer in order to make 3 cups (10mm diameter) at a spaced out position in the petri plate.

All the three cups were filled with $0.1 \mathrm{ml}(100 \mu \mathrm{l})$ of each extract $(100 \mathrm{mg} / \mathrm{ml})$ with micropipette. Each extract was tested in triplicate. Culture control and DMSO (Dimethyl sulphoxide) as solvent control were also maintained. These agar plates were set aside at room temperature for one hour for 
diffusion and then incubated at $37^{\circ} \mathrm{C}$ for $18-24$ hours. After incubation, the zone of inhibition was measured in $\mathrm{mm}$ diameter and the mean value of triplicates was recorded.

\section{Antimicrobial Susceptibility Test (AST):}

Commercially available antibiotics and antifungal agents were obtained from S.D.Fine Chemicals. Antibiotic sensitivity test was conducted against standard antibiotics such as Ampicillin $(100 \mu \mathrm{g} / \mathrm{ml})$, Ciprofloxacin $(10 \mu \mathrm{g} / \mathrm{ml})$, and Chloramphenicol $(1000 \mu \mathrm{g} / \mathrm{ml})$. Stock solutions of standards were prepared in DMSO and diluted with same to obtain required concentration. Antimicrobial susceptibility test was performed by cup plate method as described in antimicrobial screening.

\section{RESULTS AND DISCUSSION:}

The results for antimicrobial sensitivity tests of selected bacterial cultures using standard antibiotics are presented in Table 1. The antimicrobial activity of the selected plant extracts, Psydium guajava Linn, Mangifera indica, Linn, Ixora parviflora Vahl and Calotropis procera Ait. measured by the well diffusion method against nine bacterial pathogens is depicted in Table 2, Table 3, Table 4 and Table 5 respectively. The test organisms included gram positive bacteria such as and gram negative bacteria. Of all the plants investigated for antimicrobial potential, all the leaf extracts of Psydium guajava showed high antimicrobial activity against all the tested microorganisms. Methanolic leaf extract of Psydium guajava was found to exhibit highest antimicrobial activity of all its extracts.

Water leaf extract of Mangifera indica was not found be active. Methanolic leaf extract of Mangifera indica exhibited highest antimicrobial activity against all the test microorganisms in comparison to its other extracts.

Chloroform leaf extract of Mangifera. Indica showed moderate inhibitory activity against Staphylococcus aureus, Pseudomonas aeruginosa and low activity against Bacillus subtilis, Klebsiella pneumoniae and Proteus vulgaris. Petroleum ether leaf extract of Mangifera. Indica showed moderate inhibitory activity against Escheritia coli, Sarcina lutea and Staphylococcus aureus and low activity against Bacillus subtilis, Klebsiella pneumoniae, Proteus vulgaris and Pseudomonas aeruginosa. Water leaf extract of Ixora parviflora was not found to be active. Methanol leaf extract of Ixora parviflora showed high activity against Sarcina lutea and moderate activity against Staphylococcus aureus. It showed low activity against Bacillus subtilis, Escheritia coli Klebsiella pneumoniae, Pseudomonas aeruginosa, Salmonella typhi. Chloroform leaf extract of Ixora parviflora showed high activity against Sarcina lutea and moderate activity against Bacillus cereus and Staphylococcus aureus. It showed low activity against Bacillus subtilis, Escheritia coli, Klebsiella pneumoniae, Pseudomonas aeruginosa and Proteus vulgaris.

Petroleum ether leaf extract of Ixora parviflora showed high activity against Sarcina lutea and moderate activity against Staphylococcus aureus. It showed low activity against Bacillus subtilis and Salmonella typhi. Water leaf extract of Calotropis procera showed moderate activity against Bacillus cereus, Proteus vulgaris and Klebsiella pneumoniae and low activity against Bacillus subtilis, Escheritia coli and Pseudomonas aeruginosa.

Methanolic leaf extract of Calotropis procera showed moderate activity against Klebsiella pneumoniae and Pseudomonas aeruginosa and low activity against Bacillus subtilis. Chloroform leaf extract of Calotropis procera showed high activity against Klebsiella pneumoniae, Sarcina lutea, Proteus vulgaris Pseudomonas aeruginosa and moderate activity against Bacillus subtilis.

It showed low activity against Salmonella typhi. Petroleum ether leaf extract of Calotropis procera showed high activity against Klebsiella pneumoniae, Salmonella typhi, Sarcina lutea and moderate activity against Proteus vulgaris and Pseudomonas aeruginosa. It showed low activity against Bacillus subtilis and Escheritia coli.

Psidium guajava extract is reported to show the presence of tannins while that of Mangifera indica showed the presence of terpenoidal saponins, glucosides, magniferine and tannins. These compounds are known to be biologically active. Tannins have been found to form irreversible 
complexes with proline-rich proteins resulting in the inhibition of the cell protein synthesis (Hagerman and Butler, 1981). The methanolic extract of Psidium guajava was also shown to possess antibacterial effect on Bacillus subtilis, Staphylococcus aureus, Escherichia coli and Pseudomonas aeruginosa ${ }^{5}$. As per several findings in the literature a number of higher plants have been explored to exhibit antimicrobial activity due to the presence of tannins $11,12,13$.
Calotropis procera contains cardenolide, proceragenin which is reported to exhibit antibacterial activity ${ }^{8}$. All these constituents may be proposed to be responsible for antimicrobial activity obtained in the study. It is hoped that this study would lead to the establishment of some compounds that could be used to formulate new and more potent antimicrobial drugs of natural origin.

TABLE 1: ANTIMICROBIAL SENSITIVITY TEST (AST) OF SELECTED BACTERIAL CULTURES USING DIFFERENT ANTIBIOTICS

\begin{tabular}{lllll}
\hline $\begin{array}{c}\text { Sr. } \\
\text { No. }\end{array}$ & \multicolumn{1}{c}{ Microorganisms } & Ampicillin $(\mathbf{1 0 0} \boldsymbol{\mu g} / \mathbf{m l})$ & $\begin{array}{c}\text { Zone of inhibition(mm) } \\
\text { Chloramphenicol } \\
(\mathbf{1 0} \boldsymbol{\mu g} / \mathbf{m l})\end{array}$ & $\begin{array}{c}\text { Ciprofloxacin } \\
(\mathbf{1 0 0 0} \boldsymbol{\mu g} / \mathbf{m l})\end{array}$ \\
\hline 1 & Bacillus subtilis & $24 \pm 0.53$ & $10 \pm 0.53$ & $32 . \pm 1.85$ \\
2 & Bacillus cereus & $14 \pm 1.07$ & $14 \pm 0.53$ & $35 \pm 0.53$ \\
3 & Escheritia coli & $35 \pm 0.92$ & $10 \pm 0.53$ & $37 \pm 0.92$ \\
4 & Klebsiella pneumoniae & $31 \pm 1.07$ & $12 \pm 0.53$ & $35 \pm 0.53$ \\
5 & Proteus vulgaris & $30 \pm 0.92$ & $12 \pm 0.92$ & $30 \pm 0.92$ \\
6 & Pseudomonas aeruginosa & $\mathrm{NZ}$ & $20 \pm 1.41$ & $26 \pm 0.53$ \\
7 & Salmonella typhi & $19 \pm 1.07$ & $17 \pm 0.53$ & $28 \pm 0.92$ \\
8 & Sarcina lutea & $18 \pm 0.00$ & $6 \pm 0.53$ & $35 \pm 0.53$ \\
9 & Staphylococcus aureus & $27 \pm 0.53$ & $13 \pm 1.07$ & $36 \pm 0.92$ \\
\hline
\end{tabular}

NZ- No zone

All the values are mean \pm standard deviation of three determinations. All the values showed significant Difference from solvent control at $\mathrm{p}<0.05$.

TABLE 2: ANTIMICROBIAL ACTIVITY OF THE LEAF EXTRACTS OF PSYDIUM GUAJAVA LINN.

\begin{tabular}{cccccc}
\hline \multirow{2}{*}{ Sr.No } & Microorganisms & \multicolumn{4}{c}{ Zone of inhibition (mm) } \\
\cline { 2 - 5 } & & $\begin{array}{c}\text { Water } \\
\text { extract }\end{array}$ & Methanol extract & $\begin{array}{c}\text { Chloroform } \\
\text { extract }\end{array}$ & $\begin{array}{c}\text { Petroleum ether } \\
\text { extract }\end{array}$ \\
\hline 1 & Bacillus subtilis & $5 \pm 1.06$ & $8 \pm 0.53$ & $9 \pm 0.92$ & $13 \pm 1.07$ \\
2 & Bacillus cereus & $24 \pm 0$ & $30 \pm 1.85$ & $9 \pm 1.07$ & $14 \pm 1.41$ \\
3 & Escheritia coli & $11 \pm 1.08$ & $19.67 \pm 1.41$ & $9 \pm 1.60$ & $14 \pm 0.53$ \\
4 & Klebsiella pneumoniae & $10 \pm 0.92$ & $13 \pm 1.07$ & $9 \pm 0.53$ & $11 \pm 1.07$ \\
5 & Proteus vulgaris & $6 \pm 0.53$ & $7 \pm 0.92$ & $7 \pm 1.07$ & $6 \pm 1.41$ \\
6 & Pseudomonas aeruginosa & $9 \pm 1.41$ & $9 \pm 1.07$ & $10 \pm 1.41$ & $7 \pm 1.07$ \\
7 & Salmonella typhi & $9 \pm 0.53$ & $11 \pm 1.07$ & $10 \pm 0.53$ & $14 \pm 0.53$ \\
8 & Sarcina lutea & $26 \pm 1.92$ & $27 \pm 0.92$ & $8 \pm 1.07$ & $11 \pm 1.07$ \\
9 & Staphylococcus aureus & $18 \pm 0.53$ & $20 \pm 0.53$ & $19 \pm 1.07$ & $24 \pm 1.41$ \\
\hline
\end{tabular}

NZ- No zone

All the values are mean \pm standard deviation of three determinations. All the values showed significant difference from solvent control at $\mathrm{p}<0.05$.

TABLE 3: ANTIMICROBIAL ACTIVITY OF THE LEAF EXTRACTS OF MANGIFERA INDICA LINN.

\begin{tabular}{cccccc}
\hline \multirow{2}{*}{ Sr.No } & Microorganisms & \multicolumn{4}{c}{ Zone of inhibition (mm) } \\
\cline { 3 - 5 } & Bacillus subtilis & Water & Methanol extract & $\begin{array}{c}\text { Chloroform } \\
\text { extract }\end{array}$ & $\begin{array}{c}\text { Petroleum } \\
\text { ether extract }\end{array}$ \\
\hline 1 & NZ & $13 \pm 0.92$ & $6 \pm 0.53$ & $6 \pm 1.41$ \\
2 & Bacillus cereus & NZ & $17 \pm 0.53$ & $\mathrm{NZ}$ & $\mathrm{NZ}$ \\
3 & Escheritia coli & $\mathrm{NZ}$ & $14 \pm 3.20$ & $\mathrm{NZ}$ & $11 \pm 1.07$ \\
4 & Klebsiella pneumoniae & $\mathrm{NZ}$ & $9 \pm 1.07$ & $6 \pm 0.53$ & $9 \pm 1.07$ \\
5 & Proteus vulgaris & $\mathrm{NZ}$ & $6 \pm 0.53$ & $4 \pm 0.53$ & $4 \pm 0.53$ \\
6 & Pseudomonas aeruginosa & $\mathrm{NZ}$ & $11 \pm 1.07$ & $12 \pm 1.40$ & $7 \pm 1.07$ \\
\hline
\end{tabular}




\begin{tabular}{rccccc}
\hline 7 & Salmonella typhi & NZ & $7 \pm 1.07$ & NZ & NZ \\
8 & Sarcina lutea & NZ & $9 \pm 1.07$ & NZ & $13 \pm 0.53$ \\
9 & Staphylococcus aureus & NZ & $23 \pm 0.92$ & $14 \pm 1.84$ & $12 \pm 1.92$ \\
\hline
\end{tabular}

NZ- No zone

All the values are mean \pm standard deviation of three determinations. All the values showed significant difference from solvent control at $\mathrm{p}<0.05$.

TABLE 4: ANTIMICROBIAL ACTIVITY OF THE LEAF EXTRACTS OF IXORA PARVIFLORA VAHL.

\begin{tabular}{cccccc}
\hline Sr.No & Microorganisms & $\begin{array}{c}\text { Water } \\
\text { extract }\end{array}$ & Methanol extract & $\begin{array}{c}\text { Zone of inhibition (mm) } \\
\text { Chloroform extract }\end{array}$ & $\begin{array}{c}\text { Petroleum ether } \\
\text { extract }\end{array}$ \\
\hline 1 & Bacillus subtilis & $\mathrm{NZ}$ & $4 \pm 0.53$ & $6 \pm 0.53$ & $4 \pm 0.53$ \\
2 & Bacillus cereus & $\mathrm{NZ}$ & $\mathrm{NZ}$ & $10 \pm 0.53$ & $\mathrm{NZ}$ \\
3 & Escheritia coli & $\mathrm{NZ}$ & $6 \pm 0.53$ & $5 \pm 0.92$ & $\mathrm{NZ}$ \\
4 & Klebsiella pneumoniae & $\mathrm{NZ}$ & $4 \pm 0.53$ & $6 \pm 0.53$ & $\mathrm{NZ}$ \\
5 & Proteus vulgaris & $\mathrm{NZ}$ & $\mathrm{NZ}$ & $5 \pm 0.92$ & $\mathrm{NZ}$ \\
6 & Pseudomonas aeruginosa & $\mathrm{NZ}$ & $4 \pm 0.52$ & $7 \pm 1.07$ & $\mathrm{NZ}$ \\
7 & Salmonella typhi & $\mathrm{NZ}$ & $5 \pm 0.92$ & $\mathrm{NZ}$ & $7 \pm 0.92$ \\
8 & Sarcina lutea & $\mathrm{NZ}$ & $30 \pm 1.41$ & $25 \pm 0.53$ & $22 \pm 0.53$ \\
9 & Staphylococcus aureus & $\mathrm{NZ}$ & $10 \pm 0.53$ & $12 \pm 0.53$ & $12 \pm 0.53$ \\
\hline
\end{tabular}

NZ- No zone

All the values are mean \pm standard deviation of three determinations. All the values showed significant difference from solvent control at $\mathrm{p}<0.05$.

TABLE 5: ANTIMICROBIAL ACTIVITY OF THE LEAF EXTRACTS OF CALOTROPIS PROCERA AIT.

\begin{tabular}{|c|c|c|c|c|c|}
\hline \multirow[b]{2}{*}{ Sr.No } & \multirow[b]{2}{*}{ Microorganisms } & \multicolumn{4}{|c|}{ Zone of inhibition (mm) } \\
\hline & & Water extract & $\begin{array}{c}\text { Methanol } \\
\text { extract }\end{array}$ & $\begin{array}{c}\text { Chloroform } \\
\text { extract }\end{array}$ & $\begin{array}{c}\text { Petroleum } \\
\text { ether extract }\end{array}$ \\
\hline 1 & Bacillus subtilis & $7 \pm 1.07$ & $9 \pm 1.07$ & $9 \pm 0.53$ & $8 \pm 1.07$ \\
\hline 2 & Bacillus cereus & $14 \pm 1.85$ & NZ & $\mathrm{NZ}$ & NZ \\
\hline 3 & Escheritia coli & $7 \pm 1.07$ & NZ & NZ & $6 \pm 0.53$ \\
\hline 4 & Klebsiella pneumoniae & $10 \pm 0.53$ & $12 \pm 0.53$ & $15 \pm 1.07$ & $20 \pm 0.53$ \\
\hline 5 & Proteus vulgaris & $12 \pm 1.41$ & $\mathrm{NZ}$ & $12 \pm 1.41$ & $8 \pm 1.07$ \\
\hline 6 & Pseudomonas aeruginosa & $7 \pm 1.07$ & $10 \pm 0.53$ & $20 \pm 0.92$ & $8 \pm 0.53$ \\
\hline 7 & Salmonella typhi & $\mathrm{NZ}$ & NZ & $7 \pm 0.53$ & $20 \pm 0.53$ \\
\hline 8 & Sarcina lutea & $\mathrm{NZ}$ & $\mathrm{NZ}$ & $13 \pm 1.07$ & $30 \pm 1.85$ \\
\hline 9 & Staphylococcus aureus & $\mathrm{NZ}$ & $\mathrm{NZ}$ & NZ & $\mathrm{NZ}$ \\
\hline
\end{tabular}

NZ- No zone

All the values are mean \pm standard deviation of three determinations. All the values showed significant difference from solvent control at $p<0.05$.

CONCLUSION: Of all the plants investigated for antimicrobial potential, all the leaf extracts of Psydium guajava showed high antimicrobial activity against all the tested microorganisms. Methanolic leaf extract of Psydium guajava was found to exhibit highest antimicrobial activity of all its extracts. Other extracts exhibited mild to moderate activity against test organisms as reported. Further work is needed to isolate the active principle from the plant extract and to carry out pharmaceutical studies. It is hoped that this study would lead to the establishment of some compounds that could be used to formulate new and more potent antimicrobial drugs of natural origin.
ACKNOWLEDGEMENTS: The authors are thankful to the Principal, Dr. Bhanuben Nanavati College of pharmacy, Vile Parle, Mumbai, India for providing all necessary facilities and encouragement throughout research work.

\section{REFERENCES:}

1. W.H.O Drug information., Essential drugs, 7: (2), 68-73 (1993).

2. B. Patwardhan, A.D. Vaidhya and M. Chorghade, Ayurveda and natural products drug discovery. Curr.Sci., 86: 789-799 (2004).

3. F. Aquil, and I. Ahmad, Broad spectrum antibacterial and antifungal properties of certain traditionally used Indian medicinal plants. World J. Microbiol., 19: 653-657, 2003. 
4. The Wealth of India: A dictionary raw materials and Indian products, Vol -VIII ( $\mathrm{Ph}-\mathrm{Re}$ ), (Council of scientific and Industrial research, New Delhi, reprinted 2005), 286293.

5. S.I Abdelrahim, A.Z. Almagboul, M.E. Omer, A. Elegami Fitoterapia, 73: 7-8, 713-715 (2002)

6. Kirtikar and Basu Vol IV, 2440, 1979.

7. M. R.Khan, A. D. Omotoso Fitoterapia 74: (7-8): 695-698, 2003.

8. Akhtar et al., Proceragenin, an antibacterial cardenolide from Calotropis procera. Phytochemistry 31, 282, 1992.

9. A.W. Bauer, W.M. Kirby, J.C. Sherier, M. Truck Am J Clin Pathol 45: 493, 1966.

10. S.M. Finegold, and E.J. Baron, In: Diagnostic Microbiology. Edited by Finegold and Baron E.J. $7^{\text {th }}$ Edition, the C.V Mosby Co. St.Louis, 176, 1986.

\section{How to cite this article:}

Vasanti S: Evaluation of Antimicrobial Activity of Plant Extracts. Int J Pharm Sci Res 2015; 6(4): 1547-52.doi: 10.13040/IJPSR.0975$8232.6(4) .1547-52$

All @ 2013 are reserved by International Journal of Pharmaceutical Sciences and Research. This Journal licensed under a Creative Commons Attribution-NonCommercial-ShareAlike 3.0 Unported License.

This article can be downloaded to ANDROID OS based mobile. Scan QR Code using Code/Bar Scanner from your mobile. (Scanners are available on Google Playstore) 